\title{
PENGARUH MOTIVASI DAN GAYA KEPEMIMPINAN TERHADAP \\ KINERJA PEGAWAI PADA BAGIAN PROTOKOL PEMERINTAH KOTA YOGYAKARTA
}

\author{
SUTRIYONO \\ Fakultas Ekonomi Universitas Sarjanawiyata Tamansiswa Yogyakarta
}

\begin{abstract}
This study aims to: 1). To determine the effect of motivation that carried on Improved employee performance protocol Section Yogyakarta City Government. 2). To determine the effect of employee performance on the part of Yogyakarta City Government Protocol. 3). To determine the effect of leadership style on the part of the Government of Yogyakarta City Protocol.

The population in this study is an employee at the Yogyakarta city government protocol of 40 people. Samples taken are all employees of the protocol section using sampling techniques, namely Saturated samples representing the entire amount of the population.

Based on the results obtained by the regression equation is: $Y=0.244 X 1+0.671 X 2$. Based on the analysis of statistical data, indicators in this study are valid and variables are reliable. In the classic assumption test, regression models multikolonieritas free, there is no heteroscedasticity, and the normal distribution.

Through the results of the calculations have been done obtained t value of 2.072 with a significance level of 0.045 is the result of less than 0.05, which means that the hypothesis in this study receive and reject $\mathrm{Ho} \mathrm{Ha}$. In this test proved statistically that work motivation has positive influence on employee performance. Through the results of the calculations have been done obtained t value of 5.694 with a significance level of 0.000 is the result of less than 0.05, which means that the hypothesis in this study receive and reject Ho Ha. In this test is statistically proven that leadership has positive influence on employee performance.

The most powerful influence on employee performance on the protocol of Yogyakarta city government leadership is a variable that is equal to 0,671.

The results of this study are: 1). Motivation has positive influence on employee performance. 2). Leadership style has positive influence on employee performance. 3). Motivation and leadership styles affect the performance of employees in the city of Yogyakarta government protocol.

Key words: motivation, leadership style and performance.
\end{abstract}




\section{PENDAHULUAN}

Dengan perkembangan ekonomi dan majunya tekhnologi di Indonesia maka berkembang pula sasaran dan tujuan akan dicapainya oleh organisasi. Untuk mencapai tujuan organisasi, perlu adanya suatu pengembangan sumber daya manusia yang berguna untuk meningkatkan kemampuan tekhnis, konseptual dan moral pegawai sesuai dengan kebutuhan jabatan atau pekerjaan melalui pendidikan dan latihan kerja serta motivasi yang diterapkan oleh pimpinan.

Motivasi sebagai pendorong yang mengakibatkan seorang anggota organisasi mau dan rela untuk mengerahkan kemampuan dalam bentuk keahlian dan ketrampilan, tenaga dan waktunya dalam rangka pencapaian tujuan yang telah ditentukan organisasi.

Pimpinan dalam organisasi dalam memotivasi harus menyadari bahwa manusia mau dan akan bekerja dengan harapan, ia akan memenuhi kebutuhan (needs) dan keinginan ( wants) dalam kehidupannya. Kebutuhan manusia pada umumnya selalu berubah - ubah dimana apabila kebutuhan yang satu sudah terpenuhi maka kebutuhan lain akan timbul, oleh karena itu manusia akan berusaha memenuhi kebutuhan dimana ia harus bekerja lebih giat lagi untuk memperoleh imbalan yang sepadan dengan prestasi kerja yang diberikan pada tempat dimana dia bekerja. Untuk meningkatkan kinerja inilah perlu adanya suatu dorongan atau motivasi yang dilakukan oleh seorang pimpinan/manajer dalam pencapaian suatu tujuan.

Selain itu dalam melaksanakan aktifitas kegiatannya, para pimpinan mempunyai gaya tersendiri dalam proses mempengaruhi dan mengarahkan, sehingga nantinya mau bersama-sama mencapai tujuan dari perusahaan melalui pelaksanaan kerja yang telah ditetapkan. Karena masalah masalah yang dihadapi oleh perusahaan bervariasi, maka para pimpinan dituntut untuk mampu menerapkan gaya kepemimpinan yang bervariasi sesuai tujuan yang dihadapi. Gaya kepemimpinan yang sesuai dengan keadaan perusahaan dan keinginan karyawan akan mendorong motivasi kerja karyawan. Kesalahan dari gaya kepemimpinan akan mengakibatkan kegagalan dalam mencapai tujuan dan sasaran yang dikehendaki. Oleh karena itu pimpinan akan berusaha seefektif mungkin di dalam kepemimpinannya, sehingga dapat mencapai sasaran maksimal, dengan demikian produktifitas kerja akan meningkat.

\section{Rumusan Masalah}

1. Bagaimana pengaruh motivasi terhadap kinerja pegawai pada Bagian Protokol Pemerintah Kota Yogyakarta?

2. Bagaimana pengaruh Gaya Kepemimpinan terhadap kinerja pegawai pada Bagian Protokol Pemerintah Kota Yogyakarta?

3. Manakah yang mempunyai pengaruh paling kuat antara motivasi dan gaya kepemimpinan terhadap kinerja pegawai pada Bagian Protokol Pemerintah Kota Yogyakarta?

\section{Landasan Teori Motivasi}

Menurut Sardiman (2007: 73), menyebutkan motif dapat diartikan sebagai daya upaya yang mendorong seseorang untuk melakukan sesuatu. Motif dapat dikatakan sebagai daya penggerak dari dalam dan di dalam subjek untuk melakukan aktifitas-aktifitas tertentu demi mencapai suatu tujuan. Bahkan motif dapat dikatakan sebagai suatu kondisi intern (kesiapsiagaan). Berawal dari kata motif itu, maka motivasi dapat diartikan sebagai daya penggerak yang telah menjadi aktif. Motif menjadi aktif pada saat-saat tertentu, terutama bila kebutuhan untuk mencapai tujuan sangat dirasakan atau mendesak.

Menurut Malayu (2005: 143), motivasi berasal dari kata latin movere yang 
berarti dorongan atau pemberian daya penggerak yang menciptakan kegairahan kerja seseorang agar mereka mau bekerja sama, bekerja efektif, dan terintegrasi dengan segala daya upayanya untuk mencapai kepuasan. Motivasi (motivasion) dalam manajemen hanya ditujukkan pada sumber daya manusia umumnya dan bawahan khususnya. Pentingnya motivasi karena motivasi adalah hal yang menyebabkan, menyalurkan, dan mendukung prilaku manusia, supaya mau bekerja giat dan antusias mencapai hasil yang optimal. Sedangkan menurut Edwin B Flippo (dalam malayu 2005: 143), menyebutkan bahwa motivasi adalah suatu keahlian, dalam mengarahkan pegawai dan organisasi agar mau bekerja secara berhasil, sehingga para pegawai dan tujuan organisasi sekaligus tercapai.

\section{Gaya Kepemimpinan}

Siagian (2002: 62) mengemukakan bahwa kepemimpinan adalah kemampuan seseorang untuk mempengaruhi orang lain sedemikian rupa sehingga orang lain itu mau melakukan kehendak pemimpin meskipun secara pribadi hal itu mungkin tidak disenanginya. Nimran (2004: 64) mengemukakan bahwa kepemimpinan atau leadership adalah merupakan suatu proses mempengaruhi perilaku orang lain agar berperilaku seperti yang akan dikehendaki.

Sutiadi (2003: 4) mengemukakan bahwa peran kepemimpinan dalam organisasi adalah sebagai pengatur visi, motivator, penganalis, dan penguasaan pekerjaan. Yasin (2001: 6) mengemukakan bahwa keberhasilan kegiatan usaha pengembangan organisasi, sebagian besar ditentukan oleh kualitas kepemimpinan atau pengelolanya dan komitmen pimpinan puncak organisasi untuk investasi energi yang diperlukan maupun usaha-usaha pribadi pimpinan.

\section{Kinerja}

Dalam pelaksanaan pekerjaannya karyawan harus mendapat penilaian kinerja sesuai hasil kerja yang diperolehnya. Penilaian kinerja mencakup kualitas, kuantitas, pengetahuan tentang pekerjaan, kemampuan dan inisiatif serta kemampuan mengadakan kerjasama. Keharusan untuk mengadakan penilaian kinerja sercara berkala dan teliti merupakan beban bagi penilai. Karena menyangkut kepuasan karyawan, keadaan ini lebih jauh akan menuntut penilai yang baik agar dapat menghasilkan penilaian prestasi kerja yang adil untuk semua karyawan. Menurut Mulia Naustion ( $2000: 100$ ) beberapa metode dalam pelaksanaan penilaian kinerja yaitu :

1) Penetapan peringkat ( ranking method)

2) Perbandingan antara karyawan employee comparison)

3) Skala grafik ( graphic scale method)

4) Ceklis yang dibobot (weighted checklist)

5) Cerita yang menjelaskan (description essays)

Penjelasan tersebut yang diatas adalah sebagai berikut :

Bentuk penilaian kinerja ini sangat sederhana, yaitu membandingkan sesama karyawan dalam satu unit kerja. Hasil perbandingan yang akan diperoleh dengan metode ini adalah penyusunan peringkat karyawan secara sederhana. Dalam penyusunan peringkat ini organisasi mempunyai kriteria/unsur tertentu, seperti : kualitas pekerjaan, kuantitas pekerjaan, disiplin, pengetahuan tentang pekerjaan. Dengan peringkat inilah organisasi akan dapat menentukan pegawai yang punya kinerja yang baik, sehingga akan dapat ditentukan promosi atau kenaikan gaji bagi karyawan yang punya prestasi tersebut. Metode ini dilakukan dengan membandingkan seorang karyawan yang mempunyai nilai kinerja yang baik, terhadap seluruh karyawan yang ada dalam instansi atau unit kerja. Dengan adanya seorang karyawan sebagai pembanding prestasi kerja ini. Sedangkan untuk mengambil salah satu 
karyawan yang mempunyai kinerja yang baik tersebut, organisasi mempergunakan kriteria penilaian, seperti : kualitas pekerjaan yang baik, kerjasama yang baik dan pengetahuan pekerjaan yang baik pula. Merupakan suatu metode penilaian kinerja yang paling umum digunakan, metode ini hampir sama dengan metode penilaian prtestasi kerja perbandingan antara karyawan. Dalam metode penilaian ini digunakan unsur-unsur penilaian yang jelas batasannya, bukan menggunakan pembanding seorang karyawan. Unsur unsur penilaian kinerja ini sangat bervariasi, penetapan unsur ini disesuaikan dengan kepentingan organisasi dan jenis kelompok jabatan yang akan dinilai. Penilaian kinerja dengan metode ini terdirti dari sejumlah pertanyaan yang menjelaskan aneka ragam perilaku karyawan dalam melakukan suatu perkerjaan. Setiap unsur mempunyai bobot atau nilai yang diberikan pada unsur tersebut, penilaian bagi setiap karyawan yang dilakukan dengan memberikan tanda cek untuk setiap unsur penilaian ini, yang dapat menjelaskan perilaku maupun hasil kerjanya. Metode ini untuk penilaian kinerja yang mengharuskan penilaian menguraikan pokok
- pokok (unsur - unsur) kekuatan dalam melakukan pekerjaannya, dan kelemahan kelemahan dalam melaksanakan pekerjaan. Penilaian kinerja ini memberikan kebebasan pada penilai untuk menilai, sehingga akan menyebabkan banyak terjadi penilaian yang bersifat subyektif. Disini akan terlihat siapa karyawan yang disukai dan siapa karyawan yang tidak disukai oleh pimpinan. Hal ini akan menyebabkan terjadi rasa ketidakpuasan karyawan, dan akhirnya tidak akan tercapai tujuan penilaian itu sendiri.

\section{Penelitian Terdahulu}

Sebelum melakukan penelitian, maka terlebih dahulu mengamati dan mencermati hasil penelitian terdahulu yang relefan, yaitu penelitian yang dilakukan oleh Iswarjono (2012) tentang Pengaruh Motivasi dan Gaya Kepemimpinan Kepala Sekolah terhadap Kinerja Guru pada SMK Negeri 3 Kasihan Bantul Daerah Istimewa Yogyakarta.

Hasil penelitian menunjukkan bahwa motivasi kepemimpinan berpengaruh positif dan signifikan terhadap kinerja guru pada SMK Negeri 3 Kasihan Bantul Daerah Istimewa Yogyakarta.

\section{Kerangka Pemikiran}

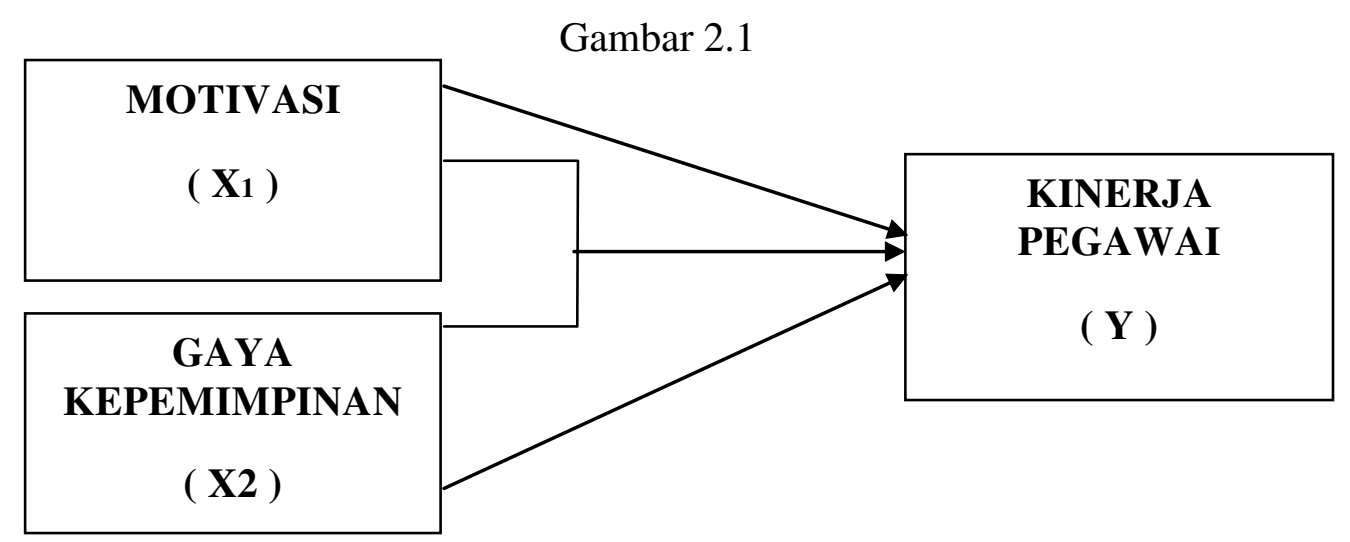

\section{METODE PENELITIAN}

\section{Sifat Penelitian}

Jenis penelitian ini adalah penelitian kuantitatif dengan tipe penelitian diskriptif dan explanatory reseach. Penelitian ini merupakan penelitian penjelasan (Explanatory research) yang akan membuktikan hubungan kausal antara variabel bebas (independent variable) yaitu variabel motivasi kerja, dan variabel kepemimpinan serta variabel terikat (dependent variable) yaitu kinerja pegawai. Serta penelitian korelasional, yaitu penelitian 
yang berusaha untuk melihat apakah antara dua variabel atau lebih memiliki hubungan atau tidak, dan seberapa besar hubungan itu serta bagaimana arah hubungan tersebut pada pegawai bagian Protokol di Pemerintah Kota Yogyakarta.

\section{Populasi dan Sampel}

Populasi dalam penelitian ini adalah pegawai bagian Protokol di Pemerintah Kota Yogyakarta berjumlah 40 pegawai.

Karena jumlah pegawai hanya 40 orang maka teknik pengambilan sampel yang digunakan adalah Nonprobability Sampling. yaitu teknik sampling yang tidak memberi peluang/kesempatan sama bagi setiap unsur atau anggota populasi untuk dipilih menjadi sampel. Pengambilan responden dilakukan dengan teknik Sampling Jenuh yaitu sampel yang mewakili jumlah populasi. Biasanya dilakukan jika populasi dianggap kecil atau kurang dari 100 (Sugiyono 2009: 118).

\section{Metode pengumpulan data}

Pada penelitian ini menggunakan metode kuesioner yaitu dengan cara menyebarkan daftar pertanyaan yang bersifat tertutup, yaitu daftar pertanyaan yang sudah disediakan alternatif jawabannya, sehingga dalam menjawab responden tinggal memilih salah satu di antara jawaban yang tersedia dan yang dirasakan paling sesuai menurut pertimbangannya.

\section{PEMBAHASAN}

\section{Pengaruh Motivasi Terhadap Kinerja Pegawai}

Hasil pengujian hipotesis (H1) telah membuktikan terdapat pengaruh antara motivasi terhadap kinerja pegawai. Melalui hasil perhitungan yang telah dilakukan diperoleh nilai t hitung sebesar 2,072 dengan taraf signifikansi hasil sebesar 0,045 tersebut lebih kecil dari 0,05, yang berarti bahwa hipotesis dalam penelitian ini menerima $\mathrm{Ha}$ dan menolak Ho. Pada pengujian ini secara statistik membuktikan bahwa motivasi kerja berpengaruh positif terhadap kinerja pegawai. Hal mempunyai arti bahwa ada pengaruh antara variabel motivasi terhadap kinerja pegawai pada bagian protokol pemerintah Yogyakarta. Hasil ini mendukung penelitian sebelumnya oleh Iswarjono (2012:63) yang menyatakan bahwa ada pengaruh positif dan signifikan antara motivasi kerja terhadap kinerja pegawai.

Pengaruh Kepemimpinan Terhadap Kinerja Pegawai

Hasil pengujian hipotesis (H2) telah membuktikan terdapat pengaruh antara gaya kepemimpinan terhadap kinerja pegawai. Melalui hasil perhitungan yang telah dilakukan diperoleh nilai $\mathrm{t}$ hitung sebesar 5,694 dengan taraf signifikansi hasil sebesar 0,000 tersebut lebih kecil dari 0,05 , yang berarti bahwa hipotesis dalam penelitian ini menerima Ha dan menolak Ho. Pada pengujian ini secara statistik membuktikan bahwa kepemimpinan berpengaruh positif terhadap kinerja pegawai. Hal mempunyai arti bahwa ada pengaruh antara variabel kepemimpinan terhadap pegawai pada bagian protokol pemerintah Yogyakarta. Hasil ini mendukung penelitian sebelumnya oleh Iswarjono (2012)yang menyatakan bahwa ada pengaruh positif dan signifikan antara kepemimpinan terhadap kinerja pegawai.

\section{KESIMPULAN DAN SARAN KESIMPULAN}

1. Berdasarkan hasil penelitian, diperoleh persamaan regresi adalah : $\mathrm{Y}=0.244 \mathrm{X} 1+0.671 \mathrm{X} 2$. Berdasarkan analisis data statistik, indikator-indikator pada penelitian ini bersifat valid dan variabelnya bersifat reliabel. Pada pengujian asumsi klasik, model regresi bebas multikolonieritas, tidak terjadi heteroskedastisitas, dan berdistribusi normal.

2. Melalui hasil perhitungan yang telah dilakukan diperoleh nilai $\mathrm{t}$ hitung sebesar 2,072 dengan taraf signifikansi hasil sebesar 0,045 tersebut lebih kecil dari 0,05, yang berarti bahwa hipotesis dalam 
penelitian ini menerima $\mathrm{Ha}$ dan menolak Ho. Pada pengujian ini secara statistik membuktikan bahwa motivasi kerja berpengaruh positif terhadap kinerja pegawai.

3. Melalui hasil perhitungan yang telah dilakukan diperoleh nilai $\mathrm{t}$ hitung sebesar 5,694 dengan taraf signifikansi hasil sebesar 0,000 tersebut lebih kecil dari 0,05 , yang berarti bahwa hipotesis dalam penelitian ini menerima $\mathrm{Ha}$ dan menolak Ho. Pada pengujian ini secara statistik membuktikan bahwa kepemimpinan berpengaruh positif terhadap kinerja pegawai.

4. Pengaruh yang paling kuat terhadap kinerja pegawai di bagian protokol pemerintah kota yogyakarta adalah variabel kepemimpinan yaitu sebesar 0.671 .

5. Motivasi kerja dan gaya kepemimpinan berpengaruh terhadap kinerja pegawai di bagian protokol pemerintah kota yogyakarta.

\section{SARAN}

\section{Untuk Bagian Protokol}

Berdasarkan penelitian ini motivasi dan gaya kepemimpinan di Bagian Protokol Pemerintah Kota Yogyakarta memiliki peran penting terhadap kinerja para pegawai, maka dari itu perlu ditingkatkan lagi sehingga kinerja pegawai semakin baik. Diharapkan, dengan pengelolaan manajemen yang baik maka potensi yang luar biasa dari pegawai akan membuat instansi menjadi lebih baik lagi.

\section{Bagi peneliti selanjutnya}

Hasil Uji R2 menunjukkan bahwa variabel motivasi dan gaya kepemimpinan sebesar 48\%. Hal ini berarti masih ada variabel-variabel lain yang harus diperhatikan dalam penelitian ini. Penelitian-penelitian lebih lanjut, hendaknya menambah variabel lain yang dapat mempengaruhi kinerja pegawai, karena dengan semakin baik kinerja dari pegawai maka akan berpengaruh baik juga bagi instansi di Bagian Protokol.

\section{DAFTAR PUSTAKA}

Ghozali, Imam. 2005. Aplikasi Analisis Multivariate dengan Program SPSS.

Semarang: BP Universitas

Diponegoro. Semarang.

Hasibuan, Malayu S.P (2002). Manajemen Sumber Daya Manusia. Jakarta. PT. Grasindo

Hasibuan, Malayu S.P (2000: 200). Manajemen Personalia Aplikasi dalam perusahaan

Hasibuan Malayu S.P ( 2001 : 217 ) dalam buku Manajemen Dasar, Pengertian dan Masalah,

Hasibuan Malayu S.P (2005), Manajemen Sumber Daya Manusia, Edisi Revisi, Bumi Aksara, Jakarta.

Iswarjono (2012). Pengaruh Motivasi dan Gaya Kepemimpinan Kepala Sekolah terhadap Kinerja Guru pada SMK Negeri 3 Kasihan Bantul Daerah Istimewa Yogyakarta.

Moekijat ( 2001 : 28 ). Pengembangan Manajemen dan Motivasi. Bandung: Alfabeta

Nasution, Mulia. Manajemen Personalia. Jakarta: Djambatan. 2000

Nimran, Umar.2004. Perilaku Organisasi. Citra Media. Surabaya

Robbinss Stephen P., 2002. Essentials of Organizati- onal Behavior (Terjemahan), edisi Kelima, Penerbit Erlangga, Jakarta.

Sardiman. 2007. Interaksi Dan Motivasi

Belajar Mengajar. Jakarta:

PT. Raja Grafindo Persada

Siagian, S. 2002. Manajemen Sumber Daya

Manusia. Jakarta: PT Bumi Aksara.

Siagian, Sondang P. 2008. Manajemen

Sumber Daya Manusia. Jakarta: Bumi

Aksara. Simanjuntak PJ.

2005. Manajemen dan Evaluasi Kinerja, 
Jakarta: Lembaga Fakultas

Ekonomi Universitas Indonesia.

Sugiyono, 2005, Memahami Penelitian Kualitatif. Bandung. Alfabeta.

Sugiyono. 2007. "Metode Penelitian Kuantitatif Kualitatif dan $R \& D$ ”. Bandung:

Alfabeta

Sugiyono, 2008, Metode Penelitian Bisnis,

CV.Alfabeta, Bandung. Rahardjo, Mudji dan Purbudi, 1997, Manajemen Sumber Daya Manusia, UPN, Yogyakarta.

Sutiadi, H. Noermijati, dan Armanu Thoyib. 2001. "Motivasi Karyawan dan Aktivitas Manajerial Kepemimpinan: Pengaruhnya Terhadap Kinerja Karyawan". Jurnal Aplikasi Manajemen.
Vol. 94, hal 95

Umar, Husein, 2000, Riset Sumber Daya Manusia dalam Organisasi, Jakarta : PT. Gramedia Pustaka Utama.

Victor H. Vroom, Work and Motivation, (New York: John Wiley \& Son, Inc.,1964. Dikutip tidak langsung oleh Malayu S.P. Hasibuan., Organisasi dan Motivasi, (Jakarta: Bumi Aksara, 2007).

Yasin Azis, 2001. Kepemimpinan dalam Pengem- bangan Organisasi, Jurnal Lintasan Ekonomi Fakultas Ekonomi Universitas Brawijaya Malang, Volume 18 Nomor 1, Malang. 